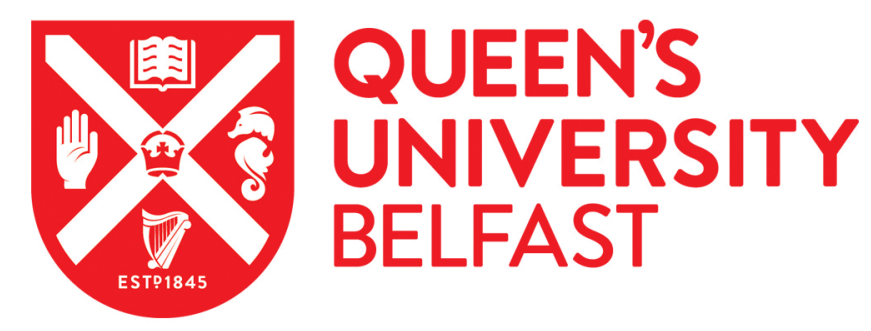

\title{
When You Put it that Way: Framing Gender Equality Initiatives to Improve Engagement among STEM Academics
}

Farrell, L., Petzel, Z. W., McCormack, T., Turner, R. N., Rafferty, K., \& Latu, I. M. (2020). When You Put it that Way: Framing Gender Equality Initiatives to Improve Engagement among STEM Academics. BioScience, 71(3), 292. [biaa136]. https://doi.org/10.1093/biosci/biaa136

\section{Published in: \\ BioScience}

\section{Document Version:}

Peer reviewed version

Queen's University Belfast - Research Portal:

Link to publication record in Queen's University Belfast Research Portal

Publisher rights

( 2020 The Author(s) 2020. Published by Oxford University Press on behalf of the American Institute of Biological Sciences.

This work is made available online in accordance with the publisher's policies. Please refer to any applicable terms of use of the publisher.

\section{General rights}

Copyright for the publications made accessible via the Queen's University Belfast Research Portal is retained by the author(s) and / or other copyright owners and it is a condition of accessing these publications that users recognise and abide by the legal requirements associated with these rights.

Take down policy

The Research Portal is Queen's institutional repository that provides access to Queen's research output. Every effort has been made to ensure that content in the Research Portal does not infringe any person's rights, or applicable UK laws. If you discover content in the Research Portal that you believe breaches copyright or violates any law, please contact openaccess@qub.ac.uk. 
Running head: FRAMING GENDER EQUALITY INITIATIVES

\title{
When You Put it that Way: Framing Gender Equality Initiatives to Improve Engagement among STEM Academics
}

Lynn Farrell, Zachary W. Petzel, Teresa McCormack, Rhiannon N. Turner, Karen Rafferty, and Ioana M. Latu

\begin{abstract}
Authors' Affiliations
Lynn Farrell (L.Farrell@qub.ac.uk) and Zachary Petzel are postdoctoral Research Fellows, Teresa McCormack and Rhiannon Turner are Professors, and Ioana Latu is a Senior Lecturer, at the School of Psychology, Queen's University Belfast. Karen Rafferty is a Professor at the School of Electronics, Electrical Engineering and Computer Science, Queen's University Belfast.
\end{abstract}

Correspondence: Lynn Farrell, School of Psychology, David Keir Building, Queen's University Belfast, Belfast, BT7 1NN, UK. E-mail: L.Farrell@qub.ac.uk

\section{Acknowledgements}

This research was supported by a UK Engineering and Physical Sciences Research Council (EPSRC) Inclusion Matters grant (EP/S011919/1). The authors would like to thank all of the research project representatives that assisted with recruitment for this study across the three partner Universities, as well as all the participants who volunteered their time for this study.

\section{Conflict of interest}

The authors declare that they have no conflict of interest.

\section{Ethical Approval}

This research was approved by the Faculty of Engineering and Physical Sciences Research Ethics Committee at Queen's University Belfast. 
FRAMING GENDER EQUALITY INITIATIVES

\begin{abstract}
A number of high-profile Gender Equality Initiatives (GEIs) aim to address women's underrepresentation in science. However, attitudes towards such initiatives can be negative. Two experiments with STEM academics examined how GEIs can be best framed to improve attitudes towards them. Study $1(N=113)$ manipulated the framing of GEI leadership (led by a man or woman) and GEI focus (benefitting men and women, or women only). Men were more supportive of GEIs benefitting both men and women due to fewer concerns of unfair treatment and more internal motivations to engage with GEIs. Women's level of support was unaffected by framing. Study $2(N=151)$ framed GEIs as either supported by university management or not, and either internally or externally driven. Support was greater for internally driven GEIs. The impact of management support depended on academics' experience with GEIs. This research makes evidence-based recommendations for the implementation of GEIs to improve their effectiveness.
\end{abstract}

Keywords: Gender equality initiatives; STEM; academics; attitudes; framing 
FRAMING GENDER EQUALITY INITIATIVES

\section{Introduction}

Women's underrepresentation in Science Technology Engineering and Mathematics (STEM) is well-documented (Schwab et al. 2016). Worldwide, women make up only 29.3\% of science researchers (UNESCO 2019). Within the UK in particular, women make up approximately $29 \%$ of those achieving higher education qualifications in core STEM subjects (WISE 2020). Men make up 57.8\% of academic faculty across UK STEM and medical subjects, with core STEM fields (e.g., engineering, mathematics, physics) and more senior positions (e.g., Professor) showing male proportions above 70\% (Advance Higher Education 2019, She Figures 2015). There is increasingly strong evidence, however, that more gender diverse organizations financially outperform those with lower female representation (McKinsey and Company 2020), highlighting one of the benefits of gender equality. Yet, without intervention the gender gap in many STEM fields will take at least a century to close (Holman et al. 2018).

Extensive research has identified gender stereotypes and biases to be a significant contributing factor towards gender inequality in STEM (e.g., National Academy of Science 2006, Master \& Meltzoff 2016). For example, evaluations of publications (e.g., KnoblochWesterwick et al. 2013), hiring decisions (e.g., Moss-Racusin et al. 2012, Reuben et al. 2014) and teaching evaluations (e.g., Morgan et al. 2016) in STEM have all been shown to demonstrate a bias in favour of males. These stereotypes and biases can have negative effects on women's STEM-related performance (e.g., Kiefer and Sekaquaptewa 2007), interest, and sense of belonging in STEM (e.g., Moss-Racusin et al. 2018). This is problematic not just from a social justice perspective but also from the standpoint of the quality of scientific

endeavours. Research shows gender diverse teams produce publications that are deemed of higher quality by peers, receiving more citations than publications by same-gender teams (Campbell et al. 2013). Underrepresented groups such as gender and ethnic minorities have 
FRAMING GENDER EQUALITY INITIATIVES

been shown to be more innovative in terms of scientific novelty, but their contributions are more often devalued or discounted (Hofstra et al. 2020). A greater inclusion of women and gender perspectives in scientific research can improve the relevance and objectivity, as well as the quality of STEM knowledge and innovation (Sánchez de Madariaga et al. 2012).

Gender equality initiatives (GEIs) were launched across academic institutions to address this underrepresentation of women in STEM. Examples include ADVANCE (NSF 2017) grants to promote institutional change favoring gender equality. Other initiatives such as Athena SWAN (UK, Ireland), SAGE (Australia) and SEA Change (US) reward academic institutions and/or departments that demonstrate sustained efforts to address gender inequality through Bronze, Silver and Gold awards which can be renewed after 3-5 years. These awards signify a commitment to address gender inequality expressed through gender equality action plans formulated by the applicant institution or department (see Advance Higher Education 2015 for more detailed information on Athena SWAN). Perhaps the longest-standing, most widespread initiative in the UK and Ireland - Athena SWAN - focuses on the representation, progression and working environment of all members of an academic community including academics, professional and support staff, as well as students. The particular actions of an Athena SWAN initiative vary across institutions as they are based on the specific needs of that institution identified by gender-disaggregated data (Rosser et al. 2019). Typical foci may include (but are not limited to) actions related to sustainable career progression, attracting and maintaining members of underrepresented categories in the staff or student population, supporting key transition points for staff including returning from taking parental leave to maintain research productivity, as well as beacon activities which disseminate best practice across other institutions. These action plans are overseen at institutional and/or departmental level by Athena SWAN committees which include representatives from academic and research staff and the undergraduate and postgraduate student body with relevant actions 
FRAMING GENDER EQUALITY INITIATIVES

implemented across these levels (e.g., networking lunches for female STEM students; mentoring opportunities for postdoctoral researchers; flexible working hours for all staff). Importantly, engagement with these initiatives has become widespread, as they are increasingly linked to eligibility for certain funding bodies in the UK and Ireland (Advance Higher Education 2015).

There have been many positive outcomes from these initiatives, such as improved self-confidence among female academics and enhanced communication regarding gender and diversity issues (Caffrey et al. 2016, Munir et al. 2013, Ovseiko et al. 2017, Tzanakou and Pearce 2019). Gender bias interventions within an academic STEM context have also been shown to increase awareness of bias, and intentions to adopt effective behavioral strategies to reduce bias (Carnes et al. 2012; Carnes et al. 2015). However, progress towards gender equality in STEM remains slow, particularly for women of color (see Bhopal and Henderson 2019a) and at more senior ranks (see Bhopal and Henderson 2019b). This indicates that cultural change to promote and sustain equality within institutions remains a challenge (Munir et al. 2013) requiring both top-down (e.g., consistent institutional leadership; AllenRamdial and Campbell 2014) and bottom-up approaches (e.g., fostering buy in from faculty; Kezar et al. 2015).

Implementing GEIs is difficult for many reasons, but an important contributing factor to their effectiveness may be negative attitudes among STEM academics towards such initiatives. Academics have expressed concerns that GEIs are simply box-ticking exercises (Tzanakou et al. 2019), or that departments are more concerned with achieving awards rather than actually implementing the changes necessary to achieve and maintain such equality (Ovseiko et al. 2017). A recent UK Equality Challenge Unit survey (ECU 2017) suggested that while some respondents believed GEIs were necessary for correcting gender inequity, others perceived them as 'lip service' without real impact - a concern expressed primarily by 
FRAMING GENDER EQUALITY INITIATIVES

men who felt women received preferential treatment in their department (although some women shared this perception).

Academic GEIs may also be met with backlash about the hiring of women to new posts, with allegations of positive discrimination (ECU 2017, Ovseiko et al. 2017) leading some women to report fears that their achievements may be attributed solely to GEIs (Ovseiko et al. 2017). Relatedly, complaints that GEIs promote positive discrimination and downplay men's achievements have also been expressed, mainly by men (Bryant et al. 2017, Ovseiko et al. 2017). Men's perception of gender issues within STEM can impact on women's opportunities for career progression as well as affect the culture of an institution (Sattari and Sanderfur 2019; see Handley et al. 2015). If GEI communications are unclear about their purpose and reasoning, they may engender resentment among men, particularly those who do not acknowledge the additional barriers that women may face in STEM careers (Sattari and Sanderfur 2019). Consequently, improving both men and women's attitudes towards GEIs will be crucial to create the cultural change necessary for gender equality efforts to thrive, for without a positive climate of support structural changes will be less effective (Kossek et al. 2003; Palmén and Schmidt 2019).

\section{The Current Research}

The current research addresses a timely and important question: what are the important factors in how an academic GEI is introduced or framed that increase support? GEIs can be multifaceted, targeting a number of different gender equality goals, however, it may be possible to frame such initiatives in a more effective way without losing sight of these underlying goals. Framing uses contextual cues to draw an individual's attention to salient aspects of a message or issue and can influence subsequent attitudes towards that issue (Holladay et al. 2003). In deciding what framing factors to investigate empirically, we drew from psychology and management research and theory on diversity initiatives, but also from 
FRAMING GENDER EQUALITY INITIATIVES

existing qualitative research (Caffrey et al. 2016, Ovseiko et al. 2017, Tzanakou et al. 2019) and experiential evidence drawn from our service work within academic GEIs. Based on a synthesis of this evidence, across two studies we examined the impact of four framing factors on GEI attitudes. The first two factors (GEI Focus and Leadership; Study 1) focus on how inclusive GEIs appear and the remaining factors (GEI Motivation and Support; Study 2) focus on how universities implement GEIs. Across both studies, we focused on UK STEM academics and assessed their individual-level outcomes such as increased positive attitudes and support for GEIs. To understand potential mechanisms for increasing support for GEIs, we also measured academics' discrimination concerns (about unfair treatment and discrimination against men or women) and motivations to engage in GEIs. These studies are important because they investigate empirically, for the first time, how GEIs can be best introduced to STEM academics to increase engagement in gender equality work.

Participants came from 17 academic departments covering the range of STEM subjects available across three UK Universities, with a particular focus on the Physical Sciences where women's underrepresentation is typically most pronounced. The Universities are all part of the Russell Group, which is a collective of high impact, research intensive Universities in the UK. Each of the participating institutions held Athena SWAN awards two Silver awards and one Bronze award. The majority of the participating departments also held departmental awards, though they varied in the type held - nine held Silver awards, five held Bronze awards and one held a Gold award. This range of experiences across departments suggests our findings are likely to generalize across departments with different experiences with GEIs.

\section{Study 1: Beneficiaries and Leaders}

Study 1 examined the impact of factors addressing inclusivity - GEI focus and leadership. 
FRAMING GENDER EQUALITY INITIATIVES

\section{GEI Focus}

STEM GEIs are typically framed to emphasize opportunities for women. For example, historically, Athena SWAN focused on advancing women's STEM careers. This may convey a message of exclusion to men and be perceived as affirmative action which tends to be evaluated less favorably by men (e.g., Beaton and Tougas 2001) if the action is viewed as a threat to their group (e.g., Moscoso et al. 2012), but also by some women (Ovseiko et al. 2017). A more inclusive approach may be to frame GEIs as benefitting and creating opportunities for both women and men. Indeed, gender equality action plans often include actions such as raising awareness of family-friendly policies for all staff, regardless of gender, and fostering positive networking between male and female staff.

Athena SWAN itself has recently expanded its remit to consider barriers to gender equality more broadly (Advance Higher Education 2015). However, it is important to empirically determine whether this framing is indeed met with positivity by both men and women. The benefit for men is that they may feel more included; for women it may help alleviate preemptive concerns that their success would be solely attributed to the GEI (Ovseiko et al. 2017). At the same time, a more inclusive framing could lead to backlash from women who believe GEIs should only focus on women to repair historical structural disadvantages. Thus, it is currently unclear whether a focus on both women and men would be generally beneficial. As a result, Study 1 empirically examined whether a GEI framed as benefitting women and men engenders more positivity and support among STEM academics, than one focused on benefitting women only.

\section{GEI Leadership}

Another consistent criticism of GEIs is that they are mainly led and championed by women (Munir et al. 2013, Tzanakou et al. 2019). Women disproportionately complete a large amount of administrative work for GEIs (Ovseiko et al. 2017) which may signal that 
FRAMING GENDER EQUALITY INITIATIVES

this work is of lower status (see Grimshaw and Rubery 2007) and a 'women's issue' only (Scambor et al. 2014). This added burden of work may negatively impact on women's career progression and function to reproduce gender inequity (Caffrey et al. 2016). Additionally, the relative paucity of men involved means there are very few male role models undertaking GEI work (Ruxton and van der Gaag 2013). Male allies working alongside women can have a strong, positive impact when confronting sexism (Drury and Kaiser 2014). Therefore, a maleled GEI may indicate that women will not have to shoulder gender equality work alone and may provide men with positive exemplars of male change agents (Government Equalities Office 2014). Moreover, exclusively female work may be perceived as lower status and lead to less engagement among men, highlighting the potential need for male GEI leadership. Conversely, it may be important to have women lead GEIs, as same-sex role models can be particularly important for women (Lockwood 2006). As such, Study 1 will additionally examine whether GEIs led by a man or a woman increase positive attitudes towards GEIs. Importantly, we also looked at how framing and participant gender interact to predict attitudes towards GEIs, in order to get a nuanced understanding of their efficiency.

\section{Method}

Participants were randomly assigned to one of four experimental conditions in which they read an email purported to be sent by a University to their staff describing a (fictitious) GEI called EQUAL that would soon be rolled out. The emails were designed to look authentic by retracting the name of the sender and the associated University. The email content manipulated GEI focus (framed to benefit men and women, or women only) and GEI leadership (led by a man or woman). Such hypothetical situation descriptions (also known as vignettes) have been commonly and effectively used in experimental research in various areas and have the advantage of ensuring high internal validity (Aguinis and Bradley, 2014). 
FRAMING GENDER EQUALITY INITIATIVES

\section{Participants and Procedure}

The study was distributed as an online survey to STEM academics through social media (e.g., Twitter) and emails from colleagues acting as representatives for the research project. One hundred and sixty-six academics based in the UK from Physics and Astronomy (23.5\%), Mathematics (24.7\%), Engineering (18.7\%), Chemistry \& Biochemistry (15.7\%) and other STEM fields (e.g., Computer Science, Statistics; 16.2\%) participated in the study. Two participants (1.2\%) failed to indicate their field. Seventeen were assigned an experimental condition but completed no questions and were excluded. For inclusion, participants had to answer two manipulation checks correctly. These checks tested whether our manipulation worked and had made an impact on our participants. This was operationalized by measuring whether participants correctly remembered the key contents of the email they had read. More specifically, multiple choice questions asked who the GEI was designed to support (e.g., men and women, women only) and who led the GEI (a man or woman). An 'I don't remember' option was provided. Thirty-three answered one or both incorrectly leaving a sample of 116 participants $\left(M_{\text {Age }}=35.55 ; S D_{\text {Age }}=11.27 ;\right.$ Range $22-71$ years). The sample was comprised of academic staff (41.38\%), postgraduate students (34.48\%), and postdoctoral researchers (24.14\%). The majority of participants were white (93.1\%) with the remainder identifying as Asian (4.3\%), mixed (0.9\%) and other (1.7\%). There were 59 women, 54 men and 3 non-binary participants. Due to the small number, the non-binary participants were excluded from the gender comparisons. Table 1 displays the numbers of men and women at each academic rank within this study. A sensitivity power analysis indicated $80 \%$ power to detect a moderate effect size $\left(\eta^{2}=.10\right)$. Of those who indicated how much experience or involvement they had with GEIs $(N=96), 62.5 \%$ had little to no experience, $28.1 \%$ had a moderate amount or a lot and $9.4 \%$ had a great deal.

[INSERT TABLE 1] 
FRAMING GENDER EQUALITY INITIATIVES

Participants could complete the survey on a laptop or desktop computer. After providing consent, participants were randomly assigned to one of four conditions in a 2 (GEI focus: Men and Women or Women Only) x 2 (GEI leadership: Male or Female) betweensubjects design, in which they read an email describing a (fictitious) GEI called EQUAL. Afterwards, participants completed a series of questionnaires. Participants were free to withdraw at any point and could choose not to respond to certain questions. Therefore, sample sizes differ across measures in the subsequent analysis. After completing the questionnaires, participants completed the Single Category Implicit Association Test (SCIAT; Karpinski and Steinman 2006). There were issues of compatibility between Inquisit and certain Operating Systems (e.g., Linux), specifically only those using Windows Operating Systems appeared able to download the plug-in necessary to complete the SC-IAT. This is a common issue with Inquisit (see https://www.millisecond.com/products/faq.aspx) and resulted in a high attrition rate for the SC-IAT (59\%). At the end of the survey, participants could choose to enter into a prize draw and were debriefed.

\section{Measures}

In addition to demographic questions, a number of measures assessed attitudes towards the GEI (see supplemental material S3). Unless otherwise indicated, these measures were adapted from previous studies dealing with attitudes towards gender equality and were rated on a scale from 1 (Strongly disagree) to 5 (Strongly agree). These questionnaires were vetted by project representatives based in STEM departments across our partner Universities.

\section{GEI Positivity (adapted from Dover et al. 2016)}

Participants rated how positively they felt towards the EQUAL initiative from 0 (extremely negative) to 100 (extremely positive). 
FRAMING GENDER EQUALITY INITIATIVES

\section{Support for the GEI (adapted from Danbold and Huo 2017, Dover et al. 2016)}

Eight items assessed support for the EQUAL initiative (e.g., "If I worked for a University with the EQUAL initiative, I would get involved in this initiative"). Negative items were reverse scored so higher scores indicated higher support for the GEI $(\alpha=.90)$.

\section{Concerns of Unfair Treatment (adapted from Dover et al. 2016)}

Three items assessed concerns regarding unfair treatment in a workplace with the EQUAL initiative (e.g., "If I were working at a University with the EQUAL initiative in place, I would worry that my gender would put me at a disadvantage"). Negative items were reverse scored. Higher scores represented fewer concerns of unfair treatment $(\alpha=.82)$ Anti-Women Discrimination (adapted from Dover et al. 2016)

Two items asked how likely participants thought a University with the EQUAL initiative would be to: (a) discriminate against women, and (b) unfairly favor men. Higher scores indicated greater anti-women discrimination $(\alpha=.87)$.

Anti-Men Discrimination (adapted from Dover et al. 2016)

Two items asked how likely participants thought a University with the EQUAL initiative would be to: (a) discriminate against men, and (b) unfairly favor women. Higher scores indicated greater anti-men discrimination $(\alpha=.87)$.

\section{Internal and External Motivations to Engage with GEIs}

While adapted from Plant and Devine (1998), additional items were also created to capture GEI-specific motivations. Five items assessed external motivations to engage with the GEI (e.g., "I would participate in initiatives like EQUAL because I would be required to"; $\alpha=.75$ ). Higher scores indicated more external motivations. Five items assessed internal motivations to engage with the GEI (e.g., "I would participate in initiatives like EQUAL because they are personally important to me"; $\alpha=.82$ ). Negative items were reverse scored so that higher scores indicated more internal motivations to engage. 
FRAMING GENDER EQUALITY INITIATIVES

\section{Single Category Implicit Association Test}

The SC-IAT is a computer-based reaction-time sorting task that requires participants to sort individual words into categories quickly and accurately. Responding should be quicker when the concepts to be categorized are more closely associated in memory. The SC-IAT examines attitudes towards a single target category - in this instance GEIs. The task was delivered by Inquisit software. Across five blocks of trials, participants had to assign words to either a category on the left by pressing the ' $\mathrm{E}$ ' key on the keyboard or a category on the right by pressing the 'I' key. First, participants categorized words as positive (e.g., helpful) or negative (e.g., harmful). Then words were categorized as positive or the names of GEIs (e.g., Athena SWAN) by pressing the 'E' key, or negative words by pressing the 'I' key. These category pairings were switched in subsequent blocks such that words were categorized as negative or GEI names by pressing the 'I' key, or positive words by pressing the 'E' key. The block order was counterbalanced across participants. A single $d$-score was produced for each participant from their SC-IAT performance (see Greenwald et al. 2003). Positive scores indicated more positive attitudes towards GEIs, and negative scores indicated more negative attitudes.

\section{Results}

Datasets are available as supplemental material (S1 and S2). We first investigated the effects of framing on male and female STEM academics using a series of 2 (GEI focus: Men and Women or Women Only) x 2 (GEI leadership: Male or Female) x 2 (Participant Gender: Men or Women) ANOVAs on each of the attitude variables. As can be seen from table 2, which summarizes the significant results, analyses showed a series of GEI focus and participant gender interactions. A full table of results (significant and non-significant) is available as supplemental material (S4).

\section{[INSERT TABLE 2]}


FRAMING GENDER EQUALITY INITIATIVES

These interactions all follow the same consistent pattern (table 3) which suggests that when the GEI is framed as benefiting both men and women (compared to just women), male STEM academics show more support and positivity towards GEIs, fewer concerns about unfair treatment, as well as more internal motivations to engage in GEIs. Across all these measures, female STEM academics were similarly positive towards GEIs, regardless of whom it was framed to benefit. Regarding concerns of unfair treatment, there was a three-way interaction between participant gender, GEI leadership and GEI focus. When a woman led the GEI, men were less concerned about unfair treatment when it was framed as benefitting both men and women as opposed to benefitting women only (see table 3 ).

\section{[INSERT TABLE 3]}

There was a main effect of GEI focus for anti-men discrimination. Participants reported less concerns of anti-men discrimination when the GEI focused on benefitting both men and women, $\left(M=2.06, M_{\text {Difference }}=0.50\right)$. For anti-women discrimination, on the other hand, there was a main effect of GEI leadership. There were less concerns about anti-women discrimination when the GEI was led by a woman $(M=2.17 ; S D=0.92)$ compared to a man $(M=2.54 ; S D=1.04)$.

\section{Mechanism for Improving GEI Attitudes}

We also conducted a moderated mediation analysis (see Hayes 2013 for a detailed description of moderated mediation; see figure 1) to investigate the factors that explain how a focus on both men and women improves male STEM academics' attitudes towards GEIs. Given that our two main attitudinal outcomes - GEI positivity and support, were significantly correlated $(r=.75, p<.001)$, we standardized these scores and created a mean composite variable which represented GEI support. Conditional indirect effects (see table 4) showed that regardless of whether a man or a woman leads the GEI, male academics show more support for GEIs that benefit both women and men (as opposed to just women), because of fewer 
FRAMING GENDER EQUALITY INITIATIVES

concerns about unfair treatment and more internal motivations to engage in gender equality work. Anti-discrimination concerns and external motivations did not seem to play a role.

\section{[INSERT FIGURE 1]}

\section{[INSERT TABLE 4]}

\section{Study 2: Motivations and Support}

Study 1 revealed that whereas female STEM academics are similarly positive about GEIs, an inclusive focus is particularly important for increasing male STEM academics' support of GEIs, primarily because such a focus decreases concerns about unfair treatment and increases internal motivation. Building on this, Study 2 directly investigated the role of GEI motivation - whether internal or external motivations were emphasized to encourage GEI participation, as well as another factor suggested by empirical research and GEI experience - management support for GEIs.

\section{GEI Motivation}

One frequent criticism of GEIs, especially since it has been tied to funding requirements, is that it is merely a box-ticking exercise (Ovseiko et al. 2017, Tzanakou et al. 2019) and thus externally motivated, rather than internally - by the valuing of diversity per se. Indeed, internal motivation emerged as an important mechanism to increase support for GEIs in Study 1. Supporting this, diversity research suggests that when the potential for learning and adaptive change through diversity is highlighted, employees feel more valued and group functioning is enhanced (Ely and Thomas 2001), whereas compulsory initiatives may produce backlash (see Ellis 1994, Kulik et al. 2007). Additionally, attempting to externally motivate individuals to reduce prejudice, through highlighting the need to comply

with social norms for example, can result in backlash effects through increased prejudice (Legault et al. 2011). Consequently, Study 2 tested the hypothesis that internally motivated GEIs increase GEI support compared to externally motivated GEIs. These GEIs will 
FRAMING GENDER EQUALITY INITIATIVES

henceforth be referred to as internally/externally driven GEIs so as to avoid confusion between this independent (manipulated) variable and the dependent (outcome) variable internal/external motivations to engage with the GEI.

\section{GEI Management Support}

A further implementation factor to consider deals with the level of support communicated by the host institution, which is a salient factor for those involved in academic diversity work. Management involvement facilitates access to resources and support for gender equality work. Without management support GEIs may find it difficult to achieve their aims on a broader scale and create sustainable culture change (Gilbert and Ivancevich 2000, Kezar et al. 2015). For example, without support from leaders in a university setting, GEI efforts and outcomes may be undermined by practices of the wider institution (Caffrey et al. 2016; Nielsen 2017). Qualitative research investigating factors that contribute to and hinder successful diversity initiatives within corporations found that all of the diversity managers interviewed identified management support and commitment as a key factor to help diversity initiatives succeed, while company leaders not fully supporting diversity was identified as a main barrier (Wentling 2004). This is echoed across the organizational literature (e.g., Cox, 2001; Evans et al. 2015; Hite and McDonald 2006; Kellough and Naff 2004; Pitts 2007). Management support may, therefore, increase the perception that GEIs will lead to real change in the host institution. Indeed, research suggests that employees react more favorably to diversity training that is supported by senior management (e.g., Jayne and Dipboye 2004). Additionally, GEIs that are actively supported by management are more likely to be perceived as authentic (Nishii et al. 2018). It is also possible that management support may be differentially important depending on whether academics have experience with GEIs. Those with little experience, being unfamiliar with how GEIs work, may view management support as a proxy for GEI effectiveness, whereas those with more GEI 
FRAMING GENDER EQUALITY INITIATIVES

experience may have developed self-efficacy in tackling gender inequality issues and, as such, be less dependent on management support in maintaining a positive attitude (Stewart et al. 2010).

Study 2 , therefore, also examined whether university management support improves attitudes towards GEIs relative to no support and whether this is moderated by GEI experience. Support was signaled by the promise of significant resources and implementation across all levels of the University. No support was signaled by limited resources allocated and implementation being attributed to an external request by the UK Equality Charter. Importantly, we planned to investigate how GEI motivation and support interactively may predict support of equality work and predicted that a GEI that is externally driven and unsupported by management would lead to the most negative attitudes.

\section{Method}

Similar to Study 1, participants were randomly assigned to one of four conditions and read a fictitious email purported to be sent by a University about the EQUAL initiative. The emails manipulated GEI motivation (internally or externally driven) and GEI support (supported by university management or not).

\section{Participants and Procedure}

One hundred and eighty academics based in the UK from Physics and Astronomy (26.7\%), Mathematics (24.4\%), Engineering (16.7\%), Chemistry and Biochemistry (14.4\%) and other STEM fields (Computer Science, Statistics etc.; 17.8\%) participated in the online survey. Twenty-eight of these participants were assigned a condition but completed no questions and were excluded, leaving a sample of 152 participants $\left(M_{\text {Age }}=35.59 ; S D_{\text {Age }}=\right.$ 11.9; Range 21-78 years). The sample was a mix of academic staff (43.42\%), postdoctoral researchers (16.45\%), and postgraduate students $(40.13 \%)$ The majority of participants were white $(88.8 \%)$ with the remainder identifying as Asian (6.6\%), mixed (2.6\%), black $(0.7 \%)$ 
FRAMING GENDER EQUALITY INITIATIVES

and other $(0.7 \%)$. There were 83 women, 68 men and 1 non-binary participant. This latter number was too low for statistical analysis; therefore, the non-binary participant was excluded from the subsequent analysis. Table 5 displays the numbers of men and women at each academic rank within this study. A sensitivity power analysis indicated $80 \%$ power to detect a moderate effect size $\left(\eta^{2}=.08\right)$.

\section{[INSERT TABLE 5]}

The procedure was identical to Study 1. Again, the study was distributed as an online survey to STEM academics through social media (e.g., Twitter) and emails from colleagues acting as representatives for the research project. After providing consent, participants were randomly assigned to a condition in a 2 (GEI motivation: Internally Driven or Externally Driven) x 2 (GEI support: Management support or No support) between-subjects design. They read a fictitious email describing the EQUAL GEI and completed the same battery of measures. Participants could opt not to answer questions, so the subsequent analysis involves different sample sizes across measures. Again, there was high SC-IAT attrition due to issues of compatibility between Operating Systems and the SC-IAT software plug-in (64\%).

Finally, participants could choose to enter into a prize draw and were debriefed.

\section{Measures}

The same measures from Study 1 were utilized assessing GEI attitudes (see supplemental material S3). They included GEI Positivity; Support for the GEI; $(\alpha=.92)$; Concerns about Unfair Treatment ( $\alpha=.81)$; Perceived Anti-Women Discrimination $(\alpha=.85)$; Perceived Anti-Men Discrimination $(\alpha=.87)$; Internal Motivations to Engage $(\alpha=.87)$ and External Motivations to Engage in GEIs $(\alpha=.70)$; and the SC-IAT.

\section{Experience with GEI work}

As in Study 1, we asked STEM academics to self-assess how much involvement or experience they have had with GEIs previously, on a scale from 1 (None at all) to 5 (A great 
FRAMING GENDER EQUALITY INITIATIVES

deal). Of those who indicated how much experience or involvement they had with GEIs $(N=125), 65.6 \%$ had little to no experience, $20.8 \%$ had a moderate amount or a lot and $13.6 \%$ had a great deal.

\section{Results}

We investigated the effects of framing on male and female STEM academics using a series of 2 (GEI motivation: Internally or Externally driven) x 2 (GEI management support: Supported or Unsupported) x 2 (Participant Gender: Men or Women) ANOVAs on each of the attitude variables. Homogeneity of Variance was violated for several ANOVAs (GEI positivity, support). However, the ratio of largest to smallest group sample size was $\leq 1.5$ in each instance, therefore, the ANOVAs should be robust to this violation (see Pallant 2007, Stevens 1996). Table 6 summarizes the significant results. A full table of results (significant and non-significant) is available as supplemental material (S4).

\section{[INSERT TABLE 6]}

These analyses demonstrated a series of main effects of GEI motivation which followed a consistent pattern. Internally driven GEIs increased both implicit $(M=0.34$, $\left.M_{\text {Difference }}=0.22\right)$ and explicit positivity $\left(M=64.10, M_{\text {Difference }}=16.79\right)$, and support for GEIs $\left(M=3.82, M_{\text {Difference }}=0.45\right)$. Internal motivations to engage with the GEI were also increased $\left(M=3.99, M_{\text {Difference }}=0.37\right)$. There were also less concerns of unfair treatment $(M=3.73$, $\left.M_{\text {Difference }}=0.40\right)$ and less external motivations to engage $\left(M=2.36, M_{\text {Difference }}=0.33\right)$ when the GEI was internally driven. Additionally, there was a main effect of gender such that women reported more support for GEIs $\left(M=3.73, M_{\text {Difference }}=0.34\right)$ regardless of condition.

The effect of management support was qualified by STEM academics' experience with GEIs, as suggested by a hierarchical multiple regression analysis (Aiken et al. 1991) with management support, GEI experience, and their interaction predicting a composite variable of GEI Positivity and Support (these outcomes were highly correlated at $r=.70$ ). 
FRAMING GENDER EQUALITY INITIATIVES

This analysis yielded a significant interaction $\beta=.29, p=.024$. As figure 2 shows, participants with little GEI experience showed more negative attitudes when the GEI was not supported, $b=-.58, p=.016$, whereas for participants with more GEI experience, there was no relationship between support and their attitudes, $b=0.20, p=.42$.

\section{[INSERT FIGURE 2]}

\section{General Discussion}

Study 1's results shed new light on the factors and mechanisms that may promote more positive academic GEI engagement, among men in particular. GEIs with a more inclusive focus benefitting both women and men were most effective at generating support among men, perhaps as they appeared less threatening to men's social group (see Moscoso et al. 2012). Men's greater support for GEIs benefitting both men and women may also be related to interest convergence (Bell, 1980), whereby women's interests in achieving gender equality in STEM are accommodated only when they converge with men's interests. Women, on the other hand, demonstrated similar levels of positivity and support regardless of condition. GEIs cannot, however, rely solely on making a case for how men will benefit to progress gender equality (Flood et al. 2018; Pease 2014). It is important to note that STEM GEIs benefitting men and women must still adhere to the important principles of advancing minority gender groups and addressing their unique concerns (see Ruxton and van der Gaag 2013). To further invest men in these issues as well as benefits for their own group, it may be crucial to raise awareness about the difficulties that women face due to gender bias in STEM (Moscoso et al. 2012). Additionally, it may be beneficial to highlight the positive impact that improved gender diversity can have on scientific knowledge itself - improving its quality (Campbell et al. 2013), novelty (Hofstra et al. 2020), relevance and objectivity (Sánchez de Madariaga et al. 2012). This will likely increase support for gender equality work among STEM academics. Together this points to the importance of experimentally examining the 
FRAMING GENDER EQUALITY INITIATIVES

attitudinal impact of GEI content also to determine which components generate greater engagement and support.

There were lower levels of anti-women discrimination concerns expressed by both men and women when the GEI was led by a female. This may be important for engaging women. This is not to suggest that male involvement is not positive or desired (e.g., Munir et al. 2013, Rosser et al. 2019). However, female leadership may be a protective factor against perceptions of female discrimination and may feel more authentic, particularly given the impact of female role models (e.g., Lockwood 2006). GEI work must be recognized and rewarded in university settings (e.g., included in promotion criteria; Caffrey et al. 2016; see Whittaker and Montgomery 2014), however, so that women are not disadvantaged by taking on such roles. It may also be of interest to determine whether a GEI led jointly by both a man and a woman may be (more) positively received by STEM academics. Female and male coleadership may provide the benefits of both authentic female leadership and a male role model for GEI work.

Importantly, we highlighted the mechanism through which a focus on both women and men led to improved attitudes towards GEIs among male scientists - they were less concerned about unfair treatment and more internally motivated. This latter finding was further supported by direct evidence in Study 2, where internally driven/motivated GEIs had positive effects regardless of gender. However, women were more supportive of GEIs than men across conditions, in line with the findings of previous research (e.g., Scarborough et al. 2019).

Finally, the impact of management support in Study 2 was moderated by academics' level of GEI experience. For participants with little to no GEI experience (65.6\%), management support was met with increased GEI support. This may also be because this group perceives management support as a proxy for effectiveness, assuming they will have 
FRAMING GENDER EQUALITY INITIATIVES

assistance from those in positions of power to get the work done. Among the fewer participants who reported involvement with GEIs, their attitudes were not influenced by management support. This may be a compensation strategy or a sign of self-efficacy - with experience they know they can and should still fight for change, regardless of management's support. Perhaps for this group more concrete support, in addition to the offer of resources, would have a stronger impact given concerns that verbal support of GEIs may not translate into necessary participation (Bhopal and Henderson 2019). With increased GEI experience more visible management role models 'walking the talk' (Munir et al. 2013, Nishii et al. 2018) may be more important. Indeed, the literature highlights consistent management support as a key factor for long-term GEI success (Allen-Ramdial and Campbell 2014) and a potential protective factor against GEI resistance (Flood et al. 2018).

\section{Practical Implications}

These results strongly suggest that attitudes towards GEIs are malleable and can be influenced by how initiatives are framed. This is good news, as it suggests we can improve STEM academics' engagement with GEIs depending on how this work is communicated. Our research points to concrete advice in this regard: motivation, focus and leadership are important factors to consider when framing GEIs to increase support among STEM academics.

First, pressurized framing of GEIs should be reduced. Internally motivated GEIs appear a powerful means of increasing positivity and support among both male and female STEM academics. Certain compulsory actions may be required to reach those who would not voluntarily participate (Bezrukova et al. 2016), however, compelling GEI engagement is likely to be counterproductive (e.g., Legault et al. 2011). Individuals are more likely to want to engage with GEIs when they perceive the value of diversity and feel they have some autonomy over their involvement as evidenced by increased support for internally driven 
FRAMING GENDER EQUALITY INITIATIVES

GEIs in the current study. GEIs should strive to emphasize their intrinsic value in relevant communications, as opposed to compulsory or legal requirements.

Second, a more inclusive framing of GEIs (i.e., providing opportunities for all genders) should promote further engagement from men, meaning women will not have to shoulder GEI work alone. This may help integrate GEI actions more effectively into policy (see Ruxton and van der Gaag 2013). GEIs framed as benefitting both women and men may lessen the perception that gender equality is a 'women's issue' that runs counter to the interests of men with no benefits for them (see Ruxton and van der Gaag 2013).

Finally, GEI information should be framed differently depending on the targets (e.g., see Cheng et al. 2011, see Slater 1996). For example, our findings suggest that female GEI leadership may be an important factor for engaging women and management support may be important for engaging those with little GEI experience, suggesting that communications about GEIs should be nuanced for different groups, as there isn't a "one size fits all” framing of gender equality work.

\section{Limitations \& Future Directions}

This research focused on binary gender, in line with the majority of research and initiatives in this domain (see García Johnson and Otto 2019). With too few non-binary participants, our analyses compared men and women only. Future research should examine whether these results generalize to gender-diverse individuals by actively recruiting from this population and also conducting qualitative studies such as interviews with non-binary participants. Additionally, it would be beneficial to examine the attitudinal impact of a GEI that emphasizes benefits for all genders, not just men and women. It is important that STEM GEIs engage and benefit individuals of all genders.

This research also lacked an intersectional approach considering other important social identities in addition to gender (see Crenshaw 1991). Our samples were predominantly 
FRAMING GENDER EQUALITY INITIATIVES

white and factors such as sexuality were not examined, therefore, we were unable to compare results across these additional categories. Together these limitations demonstrate the need for more targeted recruitment in future research, such as stratified sampling, with additional relevant social identities factored into the design.

Additionally, as the current studies were concerned solely with how the framing of GEIs can affect academics' attitudes, we did not immerse participants in the particular GEIs being described. It remains of interest to explore how participants' attitudes towards GEIs may change after they actually participate in an equality initiative; particularly one framed as internally driven, providing opportunities for men and women, and led by a woman, as these factors generated the most support across this research. The content of the GEI would need to be carefully considered here to ensure maximum alignment with the framing and adherence to the key aim of promoting gender equality. This represents an important avenue for future research.

It may also be important to more closely consider the terminology used to label gender initiatives themselves. Throughout this research we referred to and assessed attitudes towards gender equality initiatives. This is also typically how these initiatives are described. However, there is a difference between gender equality and gender equity. Gender equality seeks to provide the same opportunities and treatment to all genders, whereas gender equity seeks to provide fair treatment for different genders based on their respective needs - this may involve, for example, providing different opportunities to women to compensate for their historical structural disadvantages (see Binagwaho 2020). It may be of interest to examine whether there is more positivity and support for gender initiatives described in terms of equality or equity as this may highlight further importance nuances in academics' attitudes towards gender initiatives, particularly regarding perceptions of unfair treatment. Both 
FRAMING GENDER EQUALITY INITIATIVES

quantitative and complementary qualitative work in these areas are important for future research.

Finally, the influence of framing on attitudes towards GEIs points to its importance but also highlights the potential serious limitations of GEIs that are framed ineffectively. Such GEIs will engender less support from academics limiting their ability to create sustainable change. In certain cases, however, they may even provoke backlash and counterproductively increase prejudice against women in STEM (see Legault et al. 2011) Careful framing of GEIs is important to increase support for these initiatives and potentially prevent inadvertent negative consequences. However, given the risk of unintended backlash from current GEIs, it is also important for future research to explore the effectiveness of other forms of intervention to produce meaningful gender equality. Adopting policies and practices that normalize and prioritize gender equality may, for example, facilitate equality efforts more so than stand-alone initiatives (Whittaker and Montgomery 2014). Nevertheless, it remains important to understand how to improve attitudes towards gender equality work so that this culture change is welcomed and supported.

\section{Conclusion}

This research demonstrates that the framing of GEIs can have a significant impact on attitudes. This should be considered when universities introduce new or existing GEIs to their staff and students to increase positivity, support, and internal motivations to engage with gender equality work. We hope this research acts as a launching point for further, nuanced examinations in this domain. 
FRAMING GENDER EQUALITY INITIATIVES

\section{References}

Advance Higher Education. 2015. Athena SWAN charter. (8 January 2020;

https://www.ecu.ac.uk/equality-charters/athena-swan/about-athena-swan/history-ofathena-swan/)

Advance Higher Education. 2019. Equality in higher education: staff statistical report 2019. (17 August 2020; https://www.advance-he.ac.uk/knowledge-hub/equality-higher-educationstatistical-report-2019)

Aguinis H, Bradley KJ. 2014. Best practice recommendations for designing and implementing experimental vignette methodology studies. Organizational Research Methods, 17: 351371.

Aiken LS, West SG, Reno RR. 1991. Multiple regression: Testing and interpreting interactions. Sage.

Allen-Ramdial SAA, Campbell AG. 2014. Reimagining the pipeline: Advancing STEM diversity, persistence, and success. BioScience, 64: 612-618.

Beaton AM, Tougas F. 2001. Reactions to affirmative action: Group membership and social justice. Social Justice Research 14: 61-78.

Bezrukova K, Spell CS, Perry JL, Jehn KA. 2016. A meta-analytical integration of over 40 years of research on diversity training evaluation. Psychological Bulletin 142: 1227-1274.

Bhopal K, Henderson H. 2019a. Competing inequalities: gender versus race in higher education institutions in the UK. Educational Review: 1-17.

Bhopal K, Henderson H. 2019b. Advancing Equality in Higher Education: An Exploratory Study of the Athena SWAN and Race Equality Charters. (16 January 2020; https://www.birmingham.ac.uk/Documents/college-socialsciences/education/reports/advancing-equality-and-higher-education.pdf) 
FRAMING GENDER EQUALITY INITIATIVES

Binagwaho A. 2020. The difference between gender equity and equality—and why it matters. (16 September 2020: https://fortune.com/2020/03/25/gender-equality-and-equity-iwdwomens-education/)

Bryant LD, Burkinshaw P, House AO, West RM, Ward V. 2017. Good practice or positive action? Using Q methodology to identify competing views on improving gender equality in academic medicine. BMJ open 7: e015973.

Caffrey L, Wyatt D, Fudge N, Mattingley H, Williamson C, McKevitt C. 2016. Gender equity programmes in academic medicine: a realist evaluation approach to Athena SWAN processes. BMJ open 6: e012090.

Campbell LG, Mehtani S, Dozier ME, Rinehart J. 2013. Gender-heterogeneous working groups produce higher quality science. PloS one, 8: e79147.

Carnes M, Devine PG, Isaac C, Manwell LB, Ford CE, Byars-Winston A, ... Sheridan J. 2012. Promoting institutional change through bias literacy. Journal of Diversity in Higher Education, 5: 63.

Carnes M, Devine PG, Manwell LB, Byars-Winston A, Fine E, Ford CE, ... Palta M. 2015. Effect of an intervention to break the gender bias habit for faculty at one institution: a cluster randomized, controlled trial. Academic medicine: journal of the Association of American Medical Colleges, 90: 221.

Cheng T, Woon DK, Lynes JK. 2011. The use of message framing in the promotion of environmentally sustainable behaviors. Social Marketing Quarterly, 17: 48-62.

Cox T. Jr. 2001. Creating the Multicultural Organization: A Strategy for Capturing the Power of Diversity. San Francisco, CA: Jossey-Bass.

Crenshaw K. 1991. Mapping the margins: intersectionality, identity politics, and violence against women of color. Stanford Law Review 43: 1241-1299. 
FRAMING GENDER EQUALITY INITIATIVES

Danbold F, Huo YJ. 2017. Men's defense of their prototypicality undermines the success of women in STEM initiatives. Journal of Experimental Social Psychology 72: 57-66.

Dover TL, Major B, Kaiser CR. 2016. Members of high-status groups are threatened by prodiversity organizational messages. Journal of Experimental Social Psychology 62: 58-67.

Drury BJ, Kaiser CR. 2014. Allies against sexism: The role of men in confronting sexism. Journal of Social Issues 704: 637-652.

Ellis C. 1994. Diverse approaches to managing diversity. Human Resource Management 33: 79109.

Ely RJ, Thomas, DA. 2001. Cultural diversity at work: The effects of diversity perspectives on work group processes and outcomes. Administrative science quarterly 46: 229-273.

[ECU] Equality Challenge Unit. 2017. ASSET 2016: experiences of gender equality in STEMM academia and their intersections with ethnicity, sexual orientation, disability and age. UK: Unit EC. (20 January 2020; http://www.ecu.ac.uk/wp-content/uploads/2017/10/ECUsASSET-report-November-2017.pdf)

Evans M, Edwards M, Burmester B, May D. 2014. 'Not yet 50/50'-barriers to the progress of senior women in the Australian public service. Australian Journal of Public Administration 73: 501-510.

Flood M, Dragiewicz M, Pease B. 2018. Resistance and backlash to gender equality: An evidence review. (21 September 2020; https://eprints.qut.edu.au/119246/1/Resistance\%2Band\%2BBacklash\%2Bto\%2BGender \%2BEquality\%2BEvidence\%2BReview\%2B2018.pdf)

García Johnson CP, Otto K. 2019. Better together: A model for women and LGBTQ equality in the workplace. Frontiers in psychology 10: 272.

Gilbert JA, Ivancevich JM. 2000. Valuing diversity: A tale of two organizations. Academy of Management Perspectives 14: 93-105. 
FRAMING GENDER EQUALITY INITIATIVES

Greenwald AG, Nosek BA, Banaji MR. 2003. Understanding and using the implicit association test: I. An improved scoring algorithm. Journal of personality and social psychology 85: 197-216.

Government Equalities Office. 2014. Men as Change Agents for Gender Equality: Report on Policy Seminar. (20 January 2020;

https://assets.publishing.service.gov.uk/government/uploads/system/uploads/attachment data/file/396933/Report_on_Men_as_Agents_for_Change_in_Gender_Equality.pdf)

Grimshaw D, Rubery J. 2007. Undervaluing women's work. Equal Opportunities Commission.

Handley IM, Brown ER, Moss-Racusin CA, Smith JL. 2015. Quality of evidence revealing subtle gender biases in science is in the eye of the beholder. Proceedings of the National Academy of Sciences, 112: 13201-13206.

Hayes AF. 2013. Mediation, moderation, and conditional process analysis: A regression-based approach. Guilford.

Hite LM, Mc Donald KS. 2006. Diversity training pitfalls and possibilities: An exploration of small and mid-size US organizations. Human Resource Development International 9: 365-377.

Hofstra B, Kulkarni VV, Galvez SMN, He B, Jurafsky D, McFarland DA. 2020. The DiversityInnovation Paradox in Science. Proceedings of the National Academy of Sciences 117: 9284-9291.

Holladay CL, Knight JL, Paige DL, Quiñones MA. 2003. The influence of framing on attitudes toward diversity training. Human Resource Development Quarterly 14: 245-263.

Holman L, Stuart-Fox D, Hauser CE. 2018. The gender gap in science: How long until women are equally represented? PLoS Biology 16: e2004956.

Jayne MEA, Dipboye RL. 2004. Leveraging diversity to improve business performance: Research findings and recommendations for organizations. Human Resource 
FRAMING GENDER EQUALITY INITIATIVES

Management: Published in Cooperation with the School of Business Administration, The University of Michigan and in alliance with the Society of Human Resources Management 43: 409-424.

Kellough JE, Naff KC 2004. Responding to a wake-up call: An examination of federal agency diversity management programs. Administration \& society 36: 62-90.

Karpinski A, Steinman RB. 2006. The single category implicit association test as a measure of implicit social cognition. Journal of personality and social psychology 91: 16-32.

Kezar A, Gehrke S, Elrod S. 2015. Implicit theories of change as a barrier to change on college campuses: An examination of STEM reform. The Review of Higher Education 38: 479506.

Kossek EE, Markel KS, McHugh PP. 2003. Increasing diversity as an HRM change strategy. Journal of Organizational Change Management 16: 328-352.

Kulik CT, Pepper MB, Roberson L, Parker SK. 2007. The rich get richer: Predicting participation in voluntary diversity training. Journal of Organizational Behavior: The International Journal of Industrial, Occupational and Organizational Psychology and Behavior 28: 753769.

Legault L, Gutsell JN, Inzlicht M. 2011. Ironic effects of antiprejudice messages: How motivational interventions can reduce (but also increase) prejudice. Psychological Science 22: $1472-1477$.

Lockwood P. 2006. "Someone like me can be successful": Do college students need same-gender role models? Psychology of Women Quarterly 30: 36-46.

Master A, Cheryan S, Meltzoff AN. 2016. Computing whether she belongs: Stereotypes undermine girls' interest and sense of belonging in computer science. Journal of Educational Psychology, 108: 424-437. 


\section{FRAMING GENDER EQUALITY INITIATIVES}

McKinsey and Company. 2020. Diversity Wins: How inclusion matters. (19 ${ }^{\text {th }}$ August 2020; https://www.mckinsey.com/ /media/mckinsey/featured\%20insights/diversity\%20and\%20 inclusion/diversity\%20wins\%20how\%20inclusion $\% 20$ matters/diversity-wins-howinclusion-matters-vf.ashx).

Morgan HK, Purkiss JA, Porter AC, Lypson ML, Santen SA, Christner JG, ... Hammoud MM. 2016. Student evaluation of faculty physicians: gender differences in teaching evaluations. Journal of Women's Health, 25: 453-456.

Moscoso S, García-Izquierdo AL, Bastida M. 2012. A mediation model of individual differences in attitudes toward affirmative actions for women. Psychological reports 110: 764-780.

Moss-Racusin CA, Sanzari C, Caluori N, Rabasco H. 2018. Gender bias produces gender gaps in STEM engagement. Sex Roles 79: 651-670.

Munir F, Mason C, McDermott H, Morris J, Bagilhole B, Nevill M. 2013. Advancing women's careers in science, technology, engineering, mathematics and medicine: Evaluating the effectiveness and impact of the Athena SWAN charter. Equality Challenge Unit.

[NSF] National Science Foundation. 2017. ADVANCE: increasing the participation and advancement of women in academic science, technology, engineering and mathematic careers. (8 January 2020; https://www.nsf.gov/ehr/Materials/ADVANCEBrochure.pdf)

Nielsen MW. 2017. Scandinavian approaches to gender equality in academia: a comparative study. Scandinavian Journal of Educational Research 61: 295-318.

Nishii LH, Khattab J, Shemla M, Paluch RM. 2018. A multi-level process model for understanding diversity practice effectiveness. The Academy of Management Annals 12: $37-82$

Ovseiko PV, Chapple A, Edmunds LD, Ziebland S. 2017. Advancing gender equality through the Athena SWAN Charter for Women in Science: an exploratory study of women's and men's perceptions. Health research policy and systems 15: 12. 
FRAMING GENDER EQUALITY INITIATIVES

Pallant J. 2007. SPSS Survival Manual. Open University Press.

Palmén R, Schmidt EK. 2019. Analysing facilitating and hindering factors for implementing gender equality interventions in R\&I: Structures and processes. Evaluation and program planning 77: 101726.

Pease B. 2014. "New Wine in Old Bottles?" A Commentary on "What's in it for Men?" Old Question, New Data. Men and Masculinities, 17: 549-551.

Pitts DW. 2007. Implementation of diversity management programs in public organizations: Lessons from policy implementation research. International Journal of Public Administration 30: 1573-1590.

Plant EA, Devine PG. 1998. Internal and external motivation to respond without prejudice. Journal of personality and social psychology 75: 811-832.

Rosser SV, Barnard S, Carnes M, Munir F. 2019. Athena Swan and advance: effectiveness and lessons learned. The Lancet 393: 604-608.

Ruxton S, van der Gaag N. 2013. Men's involvement in gender equality-European perspectives. Gender \& Development, 21: 161-175.

Sánchez de Madariaga I, Raudma T, Eichenberger T, Hogan A, Pollitzer E, Rees T, ... Sergent S. 2012. Structural Change of Research Institutions. Enhancing Excellence, Gender Equality and Efficiency in Research and Innovation. Report of the expert group on structural change. Brussels, European Commission. (17 August 2020; https://ec.europa.eu/research/science-society/document_library/pdf_06/structuralchanges-final-report_en.pdf)

Scambor E, Bergmann N, Wojnicka K, Belghiti-Mahut S, Hearn J, Holter OG, Gärtner M, Hrženjak M, Scambor C, White A. 2014. Men and gender equality: European insights. Men and masculinities 17: 552-577. 
FRAMING GENDER EQUALITY INITIATIVES

Scarborough WJ, Lambouths III DL, Holbrook AL. 2019. Support of workplace diversity policies: The role of race, gender, and beliefs about inequality. Social science research 79: 194-210.

Schwab K, Samans R, Zahidi S, Leopold TA, Ratcheva V, Hausmann R, D’Andrea Tyson L. 2016. Global Gender Gap Report 2016. World Economic Forum. (17 August 2020; http://www3.weforum.org/docs/GGGR16/WEF_Global_Gender_Gap_Report_2016.pdf)

She Figures (2015). (17 August 2020;

https://ec.europa.eu/research/swafs/pdf/pub_gender_equality/she_figures_2015-final.pdf

Slater MD. 1996. Theory and method in health audience segmentation. Journal of health communication, 1: 267-284.

Stevens J. 1996. Applied multivariate analysis for the social sciences. Mahwa, New Jersey.

Stewart TL, Latu IM, Branscombe NR, Denney, HT. 2010. Yes we can! Prejudice reduction through seeing (inequality) and believing (in social change). Psychological Science 21: $1557-1562$.

Tzanakou C, Pearce R. 2019. Moderate feminism within or against the neoliberal university? The example of Athena SWAN. Gender, Work \& Organization, 26: 1191-1211.

UNESCO. 2019. Women in Science. (17 August 2020; http://uis.unesco.org/sites/default/files/documents/fs55-women-in-science-2019-en.pdf

Wentling RM. 2004. Factors that assist and barriers that hinder the success of diversity initiatives in multinational corporations. Human Resource Development International 7: 165-180.

Whittaker JA, Montgomery BL. 2014. Cultivating institutional transformation and sustainable STEM diversity in higher education through integrative faculty development. Innovative Higher Education, 39: 263-275.

WISE. 2020. Annual Core-STEM Stats Round Up: 2019-20. (17 August 2020; https://www.wisecampaign.org.uk/statistics/annual-core-stem-stats-round-up-2019-20/) 
FRAMING GENDER EQUALITY INITIATIVES

\section{Tables}

Table 1

Numbers of men and women at each academic rank within Study 1.

\begin{tabular}{lll}
\hline Academic Rank & Men (\%) & Women (\%) \\
\hline Academic Staff & $22(40.7 \%)$ & $26(44.1 \%)$ \\
Postdoctoral Researchers & $15(27.8 \%)$ & $13(22 \%)$ \\
Postgraduate Students & $17(31.5 \%)$ & $20(33.9 \%)$ \\
\hline
\end{tabular}


FRAMING GENDER EQUALITY INITIATIVES

\section{Table 2}

Significant results from 2 (Focus: Men and Women or Women Only) x 2 (Leadership: Male or Female) x 2 (Participant Gender: Men or Women) ANOVAs.

\begin{tabular}{lllllll}
\hline IV Effect & Outcome & $\boldsymbol{N}$ & $\boldsymbol{F}$ & $\boldsymbol{d f}$ & $\boldsymbol{p}$ & $\boldsymbol{\eta} \boldsymbol{p}^{2}$ \\
\hline Focus x Gender & GEI Positivity & 113 & 10.72 & $(1,105)$ & .001 & .09 \\
Focus & Support & 113 & 5.81 & $(1,105)$ & .018 & .05 \\
Focus x Gender & Support & 113 & 8.90 & $(1,105)$ & .004 & .08 \\
Focus & Concerns of Unfair Treatment & 108 & 13.21 & $(1,100)$ & $<.001$ & .12 \\
Focus x Gender & Concerns of Unfair Treatment & 108 & 6.06 & $(1,100)$ & .016 & .06 \\
Focus x Leadership x Gender & Concerns of Unfair Treatment & 108 & 4.87 & $(1,100)$ & .030 & .05 \\
Focus & Anti-Men Discrimination & 108 & 6.78 & $(1,100)$ & .011 & .06 \\
Leadership & Anti-Women Discrimination & 106 & 5.39 & $(1,98)$ & .022 & .05 \\
Focus & Internal Motivation to Engage & 102 & 6.60 & $(1,94)$ & .012 & .07 \\
Gender & Internal Motivation to Engage & 102 & 4.40 & $(1,94)$ & .039 & .05 \\
Focus x Gender & Internal Motivation to Engage & 102 & 4.75 & $(1,94)$ & .032 & .05
\end{tabular}

Note: IV = Independent variable. 
FRAMING GENDER EQUALITY INITIATIVES

Table 3

Contrasts of significant interaction effects between conditions for men and women separately.

GEI Focus:

Men \& Women

\section{GEI Focus:}

\section{Women Only}

$\begin{array}{llllllllll}\text { Outcome } & \text { Participant } & M & S D & M & S D & t & p & \text { Cohen's } d\end{array}$

\section{Gender}

\begin{tabular}{|c|c|c|c|c|c|c|c|c|}
\hline \multirow[t]{2}{*}{ Positivity } & Men & 80.75 & 17.44 & 62.14 & 24.67 & 3.48 & $<.001$ & 0.87 \\
\hline & Women & 62.60 & 18.47 & 67.07 & 16.87 & -0.89 & .376 & 0.25 \\
\hline \multirow[t]{2}{*}{ Support } & Men & 4.07 & .667 & 3.34 & .898 & 3.57 & $<.001$ & 0.92 \\
\hline & Women & 3.81 & .719 & 3.88 & .730 & -0.36 & .717 & 0.10 \\
\hline Concerns of Unfair & Men & 4.33 & .593 & 2.97 & 1.04 & 4.13 & $<.001$ & 1.61 \\
\hline Treatment - GEI & Women & 3.85 & .872 & 3.92 & .760 & -0.25 & .81 & 0.09 \\
\hline \multicolumn{9}{|l|}{ Leadership Female } \\
\hline Concerns of Unfair & Men & 4.11 & .485 & 3.60 & .813 & 1.65 & .10 & 0.76 \\
\hline Treatment - GEI & Women & 3.86 & .846 & 3.43 & .861 & 1.40 & .166 & 0.50 \\
\hline \multicolumn{9}{|l|}{ Leadership Male } \\
\hline Internal Motivation to & Men & 3.99 & .636 & 3.25 & .770 & 3.36 & .001 & 1.05 \\
\hline Engage & Women & 3.96 & .799 & 3.92 & .672 & 0.20 & .839 & 0.05 \\
\hline
\end{tabular}


FRAMING GENDER EQUALITY INITIATIVES

\section{Table 4}

Conditional indirect effects of GEI focus (benefiting women vs. both women and men) on support for GEIs, via several potential mechanisms.

\begin{tabular}{|c|c|c|c|c|c|}
\hline Mechanism & Participant gender & GEI leadership & $\mathbf{b}$ & SE & CI \\
\hline Concerns & Male & Woman & -.50 & .22 & $-.98,-.14$ \\
\hline about unfair & & Man & -.41 & .18 & $-.84,-.13$ \\
\hline \multirow[t]{2}{*}{ treatment } & Female & Woman & -.08 & .13 & $-.35, .17$ \\
\hline & & Man & .005 & .12 & $-.21, .28$ \\
\hline \multirow{4}{*}{$\begin{array}{l}\text { Anti-men } \\
\text { discrimination }\end{array}$} & Male & Woman & -.06 & .10 & $-.30, .11$ \\
\hline & & Man & -.03 & .06 & $-.18, .07$ \\
\hline & Female & Woman & -.03 & .05 & $-.13, .08$ \\
\hline & & Man & .005 & .04 & $-.04, .11$ \\
\hline \multirow{4}{*}{$\begin{array}{l}\text { Anti-women } \\
\text { discrimination }\end{array}$} & Male & Woman & -.0004 & .02 & $-.05, .05$ \\
\hline & & Man & .01 & .04 & $-.07, .10$ \\
\hline & Female & Woman & -.007 & .03 & $-.07, .05$ \\
\hline & & Man & .004 & .03 & $-.05, .07$ \\
\hline \multirow{4}{*}{$\begin{array}{l}\text { External } \\
\text { motivation }\end{array}$} & Male & Woman & .03 & .08 & $-.10, .20$ \\
\hline & & Man & -.10 & .08 & $-.30, .04$ \\
\hline & Female & Woman & .05 & .09 & $-.10, .27$ \\
\hline & & Man & -.08 & .07 & $-.23, .05$ \\
\hline \multirow{4}{*}{$\begin{array}{l}\text { Internal } \\
\text { motivation }\end{array}$} & Male & Woman & -.26 & .15 & $-.62,-.04$ \\
\hline & & Man & -.30 & .14 & $-.63,-.08$ \\
\hline & Female & Woman & -.002 & .10 & $-.22, .18$ \\
\hline & & Man & -.04 & .10 & $-.26, .17$ \\
\hline
\end{tabular}

Note: Significant conditional indirect effects are in bold. 
FRAMING GENDER EQUALITY INITIATIVES

Table 5

Numbers of men and women at each academic rank within Study 2.

\begin{tabular}{lll}
\hline Academic Rank & Men (\%) & Women (\%) \\
\hline Academic Staff & $30(44 \%)$ & $36(43 \%)$ \\
Postdoctoral Researchers & $12(18 \%)$ & $13(16 \%)$ \\
Postgraduate Students & $26(38 \%)$ & $34(41 \%)$ \\
\hline
\end{tabular}


FRAMING GENDER EQUALITY INITIATIVES

\section{Table 6}

Significant results from 2 (Motivation: Internally driven or Externally driven) x 2

(Management Support: Supported by the University or Not supported) x 2 (Participant

Gender: Men or Women) ANOVAs

\begin{tabular}{lllllll}
\hline IV Effect & Outcome & $\boldsymbol{N}$ & $\boldsymbol{F}$ & $\boldsymbol{d f}$ & $\boldsymbol{p}$ & $\boldsymbol{\eta \boldsymbol { p } ^ { 2 }}$ \\
\hline Motivation & GEI Positivity & 151 & 15.84 & $(1,143)$ & $<.001$ & .10 \\
Motivation & Implicit GEI Positivity & 54 & 6.09 & $(1,46)$ & .017 & .12 \\
Gender & Support & 149 & 6.18 & $(1,141)$ & .014 & .04 \\
Motivation & Support & 149 & 11.33 & $(1,141)$ & .001 & .07 \\
Motivation & Concerns of Unfair Treatment & 140 & 6.999 & $(1,132)$ & .009 & .05 \\
Motivation & Internal Motivation to Engage & 137 & 7.97 & $(1,129)$ & .006 & .06 \\
Motivation & External Motivation to Engage & 137 & 8.13 & $(1,129)$ & .005 & .06 \\
\hline
\end{tabular}

Note: IV = Independent variable. 
FRAMING GENDER EQUALITY INITIATIVES

\section{List of Figures}

Figure 1. Moderated mediation analysis to investigate the mechanism through which GEI focus improves support among male academics. Bold lines represent significant effects while dotted lines are non-significant.

Figure 2. Interaction between GEI experience and GEI management support for attitudes towards GEIs. 
FRAMING GENDER EQUALITY INITIATIVES

\section{List of Supplemental Material}

S1. Study 1 dataset.

S2. Study 2 dataset.

S3. Self-report measures for Studies 1 and 2.

S4. Table of full ANOVA results for Studies 1 and 2. 